$\$ 111$ billion). Per capita GDP grew from RMB 4689 in 2000 (CA \$857/year) to RMB 27192 in 2010(CA \$4971), an annual increase of $17 \%$. Per capita income of famers and herdsmen went from RMB 1956 in 2000 (CA \$358/year) to RMB 4085 in 2010 (CA $\$ 746 /$ year), an annual growth of $6.9 \%$, catching up with the national average.

Since the implementation of the Program, industrial infrastructure has undergone great changes. While agriculture and animal husbandry constitute a substantial part of output values, industry is becoming more important. The ratio of crop farming to primary industry in the national economy decreased sharply from $48 \%$ in 1999 to $26 \%$ in 2010 . With the transition from nomadic grazing to fenced feeding, from deforestation to afforestation and from traditional agriculture to protected agriculture, the Program has played a key role in promoting industrial restructuring and economic development. New industries in the Program Zone are being developed. For instance, Scutellaria baicalensis Georg., a species of flowering plant widely used in traditional Chinese medicine is the focus of small processing plants in Beijing. Other small industries include grape growing in Tianjin, black locust edible fungus plantations in Hebei and apricot plantations in Shanxi.

Monitoring of social and economic aspects of Phase I indicates that the Program has played an active role in reducing poverty and improving livelihoods. There were approximately 783000 low income earners in 21 sampled counties in 2010. This was a decrease of $44 \%$ from 2000 . The proportion of low income earners to total population dropped from $28 \%$ in 2000 to $16 \%$ in 2010 .

\section{Phase II Planning}

In spite of the remarkable achievements in Phase I, there is much more to do. Local ecological conditions continue to deteriorate; vegetation cover must be improved and extended, and soil erosion controls enhanced. Phase I plantings are in juvenile stages, with simple structure, low tolerance to drought and wind, and susceptible to disease and insect attacks. By 2009, the desertified land area of 5.4 million hectares in the Program Zone had yet to be fully controlled, leaving a daunting task to accomplish. Sandstorm events, although less frequent, still affect Beijing and Tianjin. Hence, it is necessary to further alleviate the hazards of sandstorms and reduce their impact by continuing and expanding the Program. Large areas of farmlands and pastures have yet to be effectively protected. Therefore, the government has launched Phase II to further alleviate the hazards of sandstorms, consol- idate and improve Phase I achievements, establish an ecological barrier in North China, improve livelihoods and build a well-off society.

\section{Goals of Phase II}

By the year 2022 Phase I achievements will be consolidated, desertified land will be under control, and the overall ecological environment improved. Ecological systems will be strengthened and a green ecological barrier in Beijing, Tianjin and North China established. Sandstorm events in Beijing and Tianjin will be infrequent. The economic structure will be optimized and sustainability improved. Forest and grassland resources will be used rationally and effectively, grass-livestock balance (carrying capacity) will be optimized. Phase II will show significant progress in the quality and efficiency of animal husbandry with incomes of farmers and herdsmen somewhat above the national average.

The government approved Phase II in 2012 with an investment of RMB 87.8 billion (CA $\$ 16$ billion). The Program Zone will be expanded from 75 counties in five provinces to 138 counties in six provinces, including Shaanxi.

\section{The main tasks of Phase II}

(1) Improve quality of existing vegetation by enhancing protection through zero grazing or enclosure on degraded and desertified grasslands and manage an area of 7 million ha of public forests;

(2) Increase vegetation cover by 3 million ha through afforestation and grasslands;

(3) Convert farmlands to forests/grasslands;

(4) Strengthen desertified lands and curb local erosion by fixing 0.4 million ha;

(5) Improve the capacity of water/soil conservation initiatives to rationalize the use of resources;

6) Develop grassland resources sustainably and promote development of animal husbandry; and,

(7) Reduce the ecological stress of the region by relocating 0.4 million people.

\section{Future Prospects}

Implementation of the Program has greatly improved the environment and enhanced regional social and economic sustainability. Phase II will expand the scope of the Program. This long-term Program will improve the overall environment of Beijing and Tianjin, and lead to further social and economic benefits for local communities.

Erratum

The paper published in The Forestry Chronicle 90(1): 96-104 (2014) should have had the following authorship designation.

\title{
Growth dynamics of successive post-fire cohorts of black spruce: Is site potential reduced?
}

\author{
by D. Côté ${ }^{1}$, C. Lupi², *, R. Gagnon², D. Lord² and H. Morin²
}

\footnotetext{
${ }^{1}$ Direction des affaires régionales du Saguenay-Lac-Saint-Jean, Ministère des Ressources naturelles; 3950, boulevard Harvey, Jonquière (Qc) G7H 8L6. ${ }^{2}$ Laboratoire décologie végétale et animale; Département de Sciences Fondamentales; Université du Québec à Chicoutimi; 555, boulevard de l'Université, Chicoutimi (Qc) G7H 2B1.

${ }^{*}$ Corresponding author, E-mail: carlo.lupi@uqac.ca
} 